\title{
ANALISIS DIMENSI KUALITAS PELAYANAN FISIOTERAPI PASIEN BPJS RAWAT JALAN DI RSSN BUKITTINGGI
}

\author{
Frit Rovendra \\ S TIKes Fort De Kock, ukittinggi

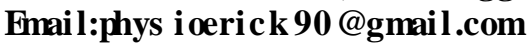

Submitte d : 05-12-2019, Re viewe r: 09-12-2019, Acce pted: 06-01-2020

\begin{abstract}
Patient's satisf ied one of indicator succed health service. Patient's satisf ied will fullfil if service giv en based on their expectation. Physiotherapy service activity, discovery time, physiotherapist attitude, environtment and nursery that is gotten will inf luence patient's satisfied. The purpose of this research is to desc ribing and analyzing the BPJ S physiotherapy service in National Stroke Hospital Bukittinggi 2019.

This research is qualitatif research by using phenomenology descriptive approach. It waS hold in National Stroke Hospital Bukittinggi by using inf orment that consists of 6 main inf ormen (employee of hospital) and 8 supporting inf ormen (BPJS patient). Technique of data collection is done by using interview deeply, observation and document analyzing.

The result of this research shows that processing (physical approvement, reliability and guarantee) is good too, yet responsiveness and emphaty of employees are not good so that influence output is satisfied.

In this resarch can be concluded that social insurance administration organization patient $i$ s qua lity toward physiotherapy service given collaboration is needed for all of aspects to improve the quality hospital service especially in fulfill patient's expectation.
\end{abstract}

\begin{abstract}
ABSTRAK
Kepuas an pasien adalah salah satu indikator keberhasilan pelayanan kesehatan. Kepuasan pasien ak an terpenuhi bila pelayanan yang diberikan telah s esuai dengan harapan mereka. Ektifitas pelayanan fis ioterapis, waktu pemulihan, prilaku fis ioterapis, lingkungan dan perawatan yang diper okh akan mempengaruhi kepuasan pasien. Tujuan penelitian ini untuk menganalisa dimensi kualitas pelayanan fis ioterapi pas ien BPJ S raw at jalan di RSSN Bukittinggi.

Penelitian ini merupakan jenis penelitian kualitatif dengan pendekatan fenomenologi deskriptif. Pelaksanaannya di RSSN Bukittinggi dengan informan yang terdiri dari 6 informan utama (petugas Rumah Sakit) dan 8 informan pendukung (pasien BPS). Teknik pengumpulan data dilakukan d engan w aw anc ara mendalam, observasidan telah dokumen.

Hasil penelitian didapatkan tema yang menunjukkan data yang ada pada proses (bukti fisk, kehandalan, jaminan) juga sudah baik, namun daya tanggap dan empati pada petugas mas ih dirasa kurang baik sehingga mempengaruhioutput yang didapat yaitu cukup puas.

Dalam penelitian ini dapat dis impulkan bahw a kualitas terhadap pelayanan fis ioterapi yang diberikan sudah cukup baik. Diperlukan kerjasama semua pihak untuk mendukung peningkatan kuatas pelayanan rumah sakit khus us nya fis ioterapi dalam memenuhi harapan pasien.
\end{abstract}

Kata kunci : kualitas, pelayanan, fis ioterapi 


\section{PENDAHULUAN}

Mutu pelayanan kesehatan adalah pelayanan kesehatan yang dapat memuaskan setiap jasa pemakai pelayanan kesehatan yang sesuai dengan tingkat kepuasan rata- rata penduduk serta penye lenggaraa nnya sesuai dengan standar dan kode etik profesi, yang dimaksud pelayanan kesehatan disini adalah sistem yang tercakup dalam pelayanan fisioterapi. Pelayanan fisioterapi juga meliputi derajat kesempurnaan pelayanan fisioterapi yang sesuai dengan standar profesi dan standar pelayanan dengan menggunakan potensi sumber daya yang tersedia di rumah sakit atau puskesmas secara wajar, efisien, dan efektif serta diberikan secara aman dan memuaskan secara norma, etika, hukum dan sosial budaya dengan memperhatikan keterbatasan dan kemampuan pemerintah, serta masyarakat. (Azwar, 2000)

$$
\text { Pelayanan kesehatan menurut }
$$

(Depkes, 2009) adalah setiap upaya yang

dise enggarakan sendiri atau secara bersama-sama dalam suatu organisasi untuk memelihara dan meningkatkan kesehatan, mencegah dan menyembuhkan penyakit serta memulihkan kesehatan perorangan, keluarga, kelompok atau pun masyarakat. Pelayanan kesehatan disini adalah sistem yang tercakup dalam pelayanan fisioterapi dimana fisioterapi berperan aktif dalam upaya meningkatkan kapasitas fisik dan kemampuan fungsional dengan menggunakan modalitas fisioterapi yang sesuai.

Fisioterapi adalah bentuk pelayanan kesehatan yang ditunjukan kepada individu dan atau kelompok untuk menge mbangkan, meme lihara, dan memulihkan gerak dan fungsi tubuh sepanjang rentang kehidupan dengan menggunakan penanganan secara manual, peningkatan gerak, peralatan (fisik, elek troterapeutis dan mekanis) pelatihan fungsi dan komunikasi. Fisioterapi memandang bahwa kesehatan gerak dan fungsi manusia untuk hidup secara sehat holistik dan sejahtera adalah sebagai hak asasi, dijadikan dasar keberadaan dan pengembangan pelayanan fisioterapi yang paripurna.(Permenkes No 65, 2015)

Dalam penelitian (Bachelor, 2015)

di Bangladesh terhadap efektifitas pelayanan fisioterapis, waktu pemulihan, perliku fisioterapi, lingkungan dan perawatan yang diperoleh. Dari hasil penelitian ditemukan bahwa terapis yang kurang ramah, kurang komunikatif dan kurang diperhatikan. Padahal harapan pasien dalam pelayanan adanya ketersediaan waktu untuk mereka, terapis yang terampil dan berpengetahuan luas, dan memberikan informasi tetag nyeri punggung dan manajemen diri.

Dibuktikan oleh penelitian (AtHamzani, Fitriyah and Alaydrus, 2018) menyatakan bahwa terdapatnya pengaruh yang kuat antara kualitas pelayanan terhadap tingkat kepuasan pasien pengguna BPJS. Kepuasan pasien merupakan suatu hal yang abstrak dan hasilnya sangat bervariasi karena pada dasarnya sangat tergantung kepada masing-masing persepsi individu. Kepuasan pasien dipengaruhi oleh beberapa faktor seperti kepesertaan pasien yang terdaftar dalam anggota BPJS, pelayanan yang didapatkan serta biaya yang harus dikeluarkan oleh pasien pada fasilitas kesehatan tingkat pertama. Kepuasan pasien akan terpenuhi bila pelayanan yang diberikan telah sesuai dengan harapan mereka.

$$
\text { Rumah Sakit Stroke Nasional }
$$

(RSSN) merupakan salah satu rumah sakit khusus tipe B di Kota Bukittinggi RSSN juga merupakan satu-satunya rumah sakit khusus nasional yang ada di Pulau Sumatera. Hal ini membuat RSSN dikunjungi oleh pasien dari berbagai daerah, termasuk pasien dari luar Provinsi Sumatera Barat. RSSN menyelenggarakan berbagai pelayanan kesehatan antara lain pelayanan rawat jalan, rawat inap, gawat 
darurat dan pelayanan pendukung lainnya seperti poli fisioterapi.(RSSN, 2017)

$$
\text { Adapun data komplain yang sering }
$$

diterima RSSN Bukittinggi adalah mengenai administrasi, prosedur pelayanan, komunikasi dan sikap petugas. Pada survei pendahulan yang dilakukan oleh peneliti didapatkan bahwa sebagian besar pasien yang mengalami kasus stroke yang menjalani program rehabilitasi di poli fisioterapi RSSN Bukittinggi Setelah dilakukan wawancara terhadap pasien tersebut rata-rata mengeluh kurang puas dengan kualitas pelayanan yang dilakukan seperti nomor antrian yang lama mulai dari loket pendaftaran pasien BPJS, alur yang ribet, waktu tunggu yang la ma untuk konsul dengan dokter spesialis sampai dengan pelaksanaan fisiotera pi serta adanya terapis kurang komunikat if.

Ada pun fenomena lainnnya dilapangan, bahwa pasien seharusnya dilakukan terapi $3 x$ seminggu, namun dikarenakan waktu tunggu yang lama, jarak tempuh yang jauh serta alur yang panjang maka pasien memilih terapi $1-2 x$ dalam seminggu. Ini menyebabkan tingkat kepuasan pasien menjadi terganggu sehingga berdampak penyembuhan penyakit akan menjadi lama dan adanya penambahan kunjungan terapi berulang kali.

\section{METODE PENELITIAN}

Penelitian ini bertujuan untuk menganalisa dimensi kualitas pelayanan fis ioterapi pasien BPJS raw at jalan di RSSN Bukittinggi Dis ain penelitian ini adalah penelitian kualitatif dengan pendekatan fenomenologi desk riptif yang berupaya untuk mengeksploras i secara mendalam tentang kepuasan kualitas pelayanan fisioterapi di RSSN Bukittinggi Pengumpulan data dilakukan dengan waw ancara mendalam (indepth interview) menggunakan pedoman waw anc ara. Informan penelitian ini terdiri dar $i$ informan utama dan informan pendukung yang berjumlah 14 orang yaitu 1 orang Direktur Rumah Sakit, 1 orang Dokter Sp.KFR, 1 orang Ka ruangan fis ioterapi, 2 orang Petugas Raw at
J alan, 1 orang Petugas BPJ S di Rumah Sakit, 8 orang pasien raw at jalan.

\section{HASIL DAN PEM B AHASAN}

\section{B ukti fis ik}

Dimensi tangible pelayanan fisioterapi terhadap pasien peserta BPJS di RSSN Bukittinggi dalam penelitian ini juga ditunjukkan oleh lima atribut, yaitu keramahan dan kesopanan oleh petugas, kebersihan dan kerapihan ruangan rawat jalan, penataan ruangan, kelengkapan dan kebersihan alat-alat yang dipakai, serta kerapihan petugas. Berdasarkan importance performance analysis melalui tingkat kesesuaian atribut yang diperoleh dari lima atribut yang mewakili dimensi tangible, hanya dua atribut yang dikatakan sudah dapat memuaskan pasien yaitu penataan ruang rawat jalan dan kerapihan penampilan fisioterapis. Sedangkan tiga atribut lainnya dikatakan belum memuaskan pasien. Selain itu berdasarkan importance performance analysis diperoleh bahwa dimensi tangible memiliki nilai tingkat kesesuaian yang sudah memuaskan pasien.Dimensi ini menjadi penting sebagai ukuran dari pelayanan karena suatu bentuk jasa tidak bisa dilihat, dic ium dan diraba. Sebagaimana menurut (Eva, 2011) menyatakan kare na suatu bentuk jasa tidak bisa dilihat, dicium, diraba maka bukti fisik menjadi penting sebagai ukuran dari suatu pelayanan.

Dimensi bukti fisik (tangible) berkaitan dengan daya tarik fasilitas fisik, kelengkapan, dan material yang digunakan perusahaan, serta penampilan petugas. Rumah sakit memiliki bukti fisik yang baik apabila kondisi interior dan eksterior ruangan ditata secara menarik, kondisi kenyamanan dan kebersihan gedung, kerapihan dan kebersihan gedung, kerapihan dan kebersihan petugas, dan kecanggihan peralatan yang ada. 
Harapan pasien terhadap dimensi tangible merupakan keyakinan pasien sebelum menerima pelayanan yang nantinya akan dijadikan standar atau acuan dalam menilai pelayanan. (Supranto, 2011)

Item bukti fisik menunjukkan bahwa pasien merasa puas dengan sarana dan prasarana yang digunakan pasien terjaga kebersihannya, dan ruang pelayanan bersih dan rapih. Sedangkan tiga indikator kenyamanan, penampilan petugas BPJS bersih, pasien sudah merasa juga puas.

\section{Ke handalan}

Item reliability diketahui tiga indikator bahwa pasien merasa tidak puas dalam prosedur penerimaan pasien BPJS tidak berbelit-belit, kecepatan petugas BPJS pelayanan administrasi, serta petugas tidak membedakan pelayanan BPJS maupun umum. Pasien juga merasa puas mengenai petugas BPJS memberikan pelayanan sesuai prosedur, dan petugas BPJS membantu permasalahannya pasien.

$\begin{array}{crr}\text { Dimensi } & \text { reliability } & \text { pelayanan } \\ \text { fisioterapi di } & \text { RSSN } & \text { Bukittinggi }\end{array}$ terhadap pasien peserta BPJS dalam penelitian ini ditunjukkan pada kehandalan petugas pendaftaran, kehandalan pemeriksaan, ke disiplinan waktu, dan alur pelayanan. Berdasarkan importance performance analysis melalui tingkat kesesuaian dari empat atribut yang mewakili dimensi reliability, hanya ada satu atribut yang dikatakan dapat memuaskan pasien yaitu prosedur pelayanan fisioterapi untuk pasien BPJS yang tidak berbe litbe lit. Sedangkan tiga atribut lainnya belum memuaskan pasien. Ketidakpuasan ini disebabkan pasien BPS merasa petugas kesehatan lambat dalam memberikan pelayanan. Pasien merasa bahwa prosedur administrasi penerimaan pasien dilakukan dengan lambat sehingga pasien harus menunggu lama untuk mendapatkan pelayanan. Selain itu jadwal pelayanan pengobatan yang diberikan juga sering tidak tepat waktu yang disebabkan dokter datang terlambat ke rumah sakit. Sedangkan pelayanan yang tepat waktu dinilai sangat penting bagi pasien BPJS karena setiap pasien menginginkan masalah kesehatannya cepat dan segera diatasi sebagaimana yang disampaikan olh (Sri Kuntjoro, 2002) bahwa harapan utama saat pasien datang ke rumah sakit adalah kesembuhan dari penyakit yang diderita. Kesembuhan merupa kan salah satu bukti keberhasilan kinerja pe hyanan klinis, sehingga bila pasien sembuh bukan saja menunjukkan keberhasilan kinerja pelayanan, tetapi juga membuat pasien puas karena tujuan utamanya tercapai (Buda yanti, 2007)

Kehandalan dan keterampilan (reliability) adalah kemampuan untuk melakukan pelayanan sesuai yang dijanjikan dengan segera, akurat, dan memuaskan.(Walyani, E $\quad$ S.\& Purwoastuti, 2015)

Dimensi kehandalan (reliability) berkaitan dengan kemampuan rumah sakit untuk memberikan layanan yang akurat sejak pertama kali tanpa membuat kesalahan apa pun dalam penyampaian jasanya sesuai dengan waktu yang disepakati. Sebuah rumah sakit dikatakan handal kalau proses penerimaan paisen dilakukan dengan cepat dan prosedur pengadministrasian serta pembayaran yang praktis, tindakan yang cepat dan tepat terhadap pemeriksaan dan pengobatan, pemeriksaan laboratorium, kunjungan dokter, perawatan dijalankan dengan tepat serta penerimaan hasil pemeriksaan secara cepat dan tepat. Dalam hal ini kebutuhan pasien adalah kebutuhan untuk sembuh dari sakit yang dapat dicapai melalui diagnosis yang tepat dan pengobatan yang tepat pula. (Supranto, 2011) 
Menurut Potter dalam Supriyono (2003), dikemukakan pelayanan yang berkualitas perlu beberapa kriteria, antara lain : Dapat diterima, artinya pelayanan memiliki kualitas apabila dilihat dari teknis/cara, kualitas, ke mudahan, kenyamanan, menyenangkan dapat diandalkan, tepat waktu, cepat, responsif dan manusiawi.

\section{Daya Tang gap}

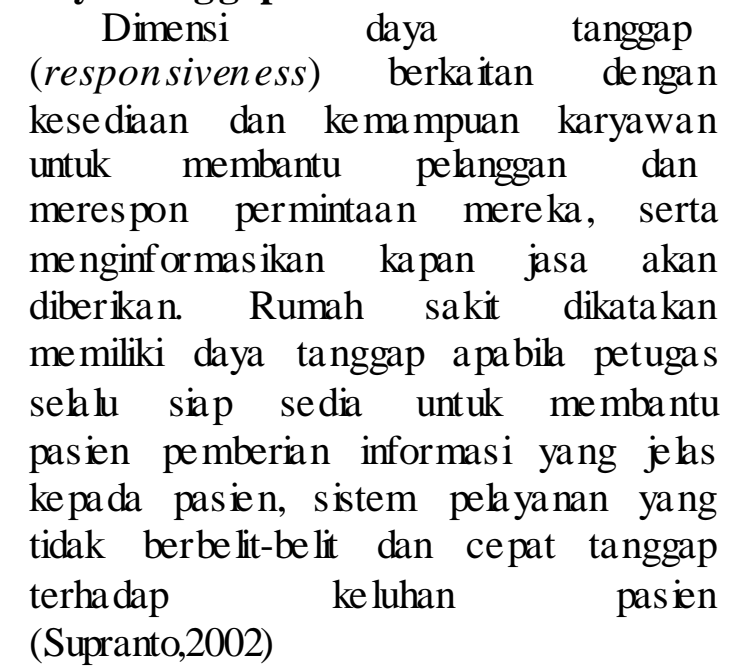

Dimensi responsiveness pelayanan fisioterapi pasien BPJS di RSSN Bukittinggi dalam penelitian ini ditunjukkan oleh empat atribut yaitu, ketanggapan dokter, kejelasan informasi oleh petugas, kerjasama antar petugas, dan ketanggapan petugas. Se orang pelanggan akan menghara pkan bahwa ia seharusnya juga dilayani dengan baik apabila pelanggan yang lainnya dilayani de ngan baik oleh penye dia jasa. Disinilah diperlukan responsivitas penyedia jasa untuk memperlakukan dan memanjakan pelanggan secara nyata, pelanggan butuh dilayani dan dihargai tanpa membedakan status sosial ekonomi (Tjptono F, 2000).

Berdasarkan

importance performance analysis melalui tingkat kesesuaian atribut pada tabel diperoleh dari empat atribut, hanya dua atribut yang dinyatakan sudah memuaskan pasien dan dua lainnya dinyatakan belum memuaskan pasien. Atribut yang sudah memuaskan pasien a da lah petugas memberikan infromasi yang jelas dan kerjasama antara dokter dan perawat yang baik. Sedangkan atribut yang belum memuaskan pasien adalah kemampuan, ketanggapan pada keluhan pasien dan tindakan yang cepat pada saat pasien membutuhkan.

Meskipun demikian, berdasarkan importance performance analysis diperoleh bahwa pelayanan fisioterapi berdasarkan dimensi reliability sudah dikatakan puas karena nilai tingkat kesesuaian dimensi ini diatas rata-rata. Artinya pelayanan sudah dinilai sigap dan cepat dalam pelayanan. Sebagaimana menurut Soraya (2011) menye butkan responsiveness yaitu respon atau kesigapan karyawan dalam membantu pelanggan dan memberikan pelayanan yang cepat dan tanggap, yang meliputi kesigapan karyawan dalam melayani pelanggan, kecepatan karyawan dalam melayani transaksi, serta penanganan keluhan pelanggan.

\section{Empati}

Dimensi empati (emphaty) berkenaan dengan kemapuan perusahaan untuk memahami masalah pelanggan dan bertindak ramah demi pelanggan. Rumah Sakit dikatakan memiliki dimensi empati apabila peduli terhadap keluhan pasien, kepedulian terhadap kebutuhan dan keinginan pasien, tidak pith pilh dalam memberikan pelayanan kepada semua pasien dan kesimpatikan dokter dan petugas terhadap pasien (Supranto,2011).

Hasil wawancara pada pasien yang menyatakan bahwa empati pada dasarnya adalah sebuah pola pekerjaan yang melekat pada fisioterapis, model empati yang disampaikan pun berbedabeda, empati harus dilakukan dengan sepenuh hati tanpa membeda-bedakan pasien satu sama lain. Beberapa pasien masih mengeluhkan perhatian 
fisioterapis yang tidak berada disamping saat melakukan terapi Hal ini membuat kecemasan pasien tentang dampak terapi yang digunakan saat melakukan terapi.

Dimensi emphaty pelayanan fisioterapi pasien BPJS di RSSN Bukittinggi dalam penelitian ini ditunjukan oleh empat atribut, yaitu keramahan petugas, perhatian petugas, pelayanan yang tanpa memandang status sos ial, serta komunikasi antara pasien dan petugas.

Berdasarkan

importance performance analysis melalui tingkat kesesuaian atribut yang diperoleh dari empat atribut yang mewakili dimensi emphaty, terdapat tiga atribut yang dikatakan sudah dapat memuaskan pasien yaitu perhatian khusus kepada pasien, perhatian terhadap keluhan pasien, pelayanan kepada pasien tanpa memandang status sosial. Sedangkan satu atribut yaitu komunikasi antara pasien dan petugas dikatakan belum memuaskan pasien. Disamping jaminan, salah satu elemen penting clinical governance lainnya adalah empati Pasien membutuhkan perhatian dan komunikasi teraupetik yang harmonis. Perhatian yang diberikan penyedia pelayanan akan dapat memberikan rasa nyaman dan aman dalam menjalani perawatan (Tjptono $\mathrm{F}$, 2000).

Penelitian Sinambela dkk. (2008), mengatakan bahwa kualitas pelayanan tercermin dari hal, diantaranya adalah : "Kesamaan hak, yaitu pelayanan yang tidak melakukan diskriminasi dilihat dari aspek apapun khususnya suku, ras, agama, golongan dan status sosiaP'. Pelayanan Kesehatan diartikan sebagai pemberian perhatian kepada masyarakat yang menyangkut atau berhubungan dengan sarana dan prasarana kesehatan termasuk tenaga kesehatan, agar masyarakat merasa aman dan terjamin dalam memeriksakan kesehatannya.

\section{Jaminan}

Dimensi jaminan (assurance) berkenaan dengan perilaku karyawan yang mampu menumbuhkan kepercayaan pelanggan terhadap perusahaan dan menciptakan rasa aman bagi pelanggan. Rumah sakit dikatakan me miliki jaminan apabila pelayanan yang diberikan rumah sakit kepada pasien disertai dengan keahlian dokter dalam menetapkan diagnosis, ketrampilan dan pengetahuan personel medis, serta jaminan dan kepercayaan terhadap pelayanan yang diberikan (Supranto, 2011).

Hasil observasi di lapangan menunjukan bahwa tenaga fisioterapis yang ada di RSSN Bukittinggi sudah memiliki latar belakang pendidikan yang memadai antara lain pendidikan Diploma, Sarajana, Profesi dan Magister yang terampil dalam menangani pasien. Jumlah tenaga fisioterapis yang ada sudah memadai, tidak ada kekurangan tenaga, komunikasi dengan pasien juga baik, pelayanan yang diberikan juga sudah sesuai dengan Standar Operasional Prosedur (SOP). Disamping itu mereka melayani pasien dengan sopan santun dan ramah tamah. Dengan demikian pasien menjadi aman dan nyaman dalam menerima pelayanan kesehatan di RSSN Bukittingi Dimensi assurance pelayanan fisioterapi pasien BPJS di RSSN Bukittinggi dalam penelitian ini ditunjukkan oleh empat atribut yaitu kemampuan menjaga kerahasiaan diagnose penyakit, keahlian dokter, perawat serta petugas lainnya, kemudian jaminan dan kepercayaan yang diberikan petugas dan ketrampilan petugas. Jaminan merupakan tolok ukur kemampuan serta pengetahuan petugas agar sepenuhnya dapat dipercaya tanpa ragu sebagai profesionalisme yang handal Kegagalan dalam memberikan jaminan kepada pasien akan berakibat 
kekhawatiran pasien untuk menerima pertolongan.

Bagi fisioterapis, aspek jaminan bentuknya adalah meyakinkan pasien dengan saling bahu membahu dengan dokter untuk menyembuhkan pasien. Antara fisioterapis dan pasien harus terjadi“simbiosa mutualisme" agar terjalin kerjasama, antara pasien dan fisioterapis, dalam berjuang melewati penyakit yang diderita pasien. Pasienpun harus diyakinkan bahwa pekerjaan fisioterapis tidak bisa secepat harapan pasien karena tindakan fisioterapi harus dibarengi dengan latihan mandiri di rumah, sehingga fisioterapis tidak bisa bekerja sendiri karena dalam aspek ini harus mampu bekerjasama dengan pasien, keluarga pasien serta dokter. Karena aspek jaminan adalah menjanjikan sesuatu atas kesembuhan pasien dan hal tersebut dipandang rehtif oleh fisioterapis.

\section{KESIM PULAN DAN SARAN}

Hakekat dari rumah sakit adalah pemenuhan dan tuntutan pasien yang mengharapkan penyelesian masalah kesehatannya pada rumah sakit. Pasien memandang bahwa hanya rumah sakit yang mampu memberikan pelayanan medis sebagai upaya penyembuhan dan pemulihan atas rasa sakit yang dideritanya. Pasien mengharapkan pelayananan yang siap, cepat, tanggap dan nyaman terhadap keluhan penyakit pasien. Dalam memenuhi kebutuhan pasien tesebut pelayanan prima menjadi utama dalam pelayanan dirumah sakit. Penelitian ini diharapkan apat menjadikan acuan dalam membuat kebijakan di layanan fisioterapi untuk mewujudkan kepuasan pasien, Mewajibkan seluruh pegawai untuk mengikuti diklat pelayanan prima,sehingga pegawai memiliki kemampuan yang lebih baik dalam memberikan pelayanan kepada pasien.

\section{TERIMA KASIH}

Terima kasih kepada Pihak Rumah Sakit Stroke Nasional Bukittinggi atas dukungan dalam penelitian ini, serta resonden yang telah ikut berpartisipasi dalam melakukan penelitian ini Selanjutnya, terima kasih kepada Institusi dan rekan-rekan yang telah memberi saran dan masukan atas penelitian ini dan dapat digunakan untuk penelitian selanjutnya.

\section{REFERENSI}

Al-Hamzani, D., Fitriyah, N. and Alaydrus, A. (2018) 'Pengaruh Kualitas Pelayanan Terhadap Tingkat Kepuasan Pasien Rawat Inap Pengguna Kartu Badan Penyelenggara Jaminan', 6(4), pp. 1593-1606. Available at: http $/ /$ ejournal ip. fis ip unmul ac. id/s ite/w pc ontent/uploads/2018/08/J urnal udah di revisi (08-20-18-03-55-42).pdf.

Azw ar (2000) Menjaga Mutu Pelayanan Kesehatan. Jakarta: Pustaka Sinar Harapan.

Bac helor, S. M. (2015) 'Satisfac tion About Physiotherapy Service Among Patients With Prolapsed Lumbar Intervertebral Satisfaction About Physiotherapy Servic e Among Patients With Prolaps ed Lumbar Intervertebral', pp. 2010-2011.

Budayanti, S. (2007) Mutu Pelayanan Kesehatan bagi Pasien Askeskin berdasarkan Standar Pelayanan Publikdi RSUD Banyumas. Univers itas J endral Soedirman Purw okerto.

Depkes, R. (2009) UU no 44 Tahun 2009 tentang Rumah Sakit. J akarta.

Eva, S. (2011) Analisis Kualitas Pelayanan Provider jasa Seluler Indosat IM3 Terhadap Kepuasan Konsumen. Semarang.

Permenkes No 65 (2015) 'Standar Pelayanan Fis ioterapi', (1662), p. 2.

RSSN (2017) Laporan A kuntabilitas Kinerja Tahun 2017. Bukittinggi

Sri Kuntjoro, Z (2002) Komitmen Organisasi . Bandung: Erlangga.

Supranto (2011) Pengukuran Tingkat Kepuasan Pelanggan Untuk Menaik kan 
Pangsa Pasar. c etakan ke. Jakarta: PT Rineka Cipta.

Tjptono. F. 2000. Manajemen Jasa. Penerbit Adi. Yogyakarta
Walyani, E S.\& Purwoastuti, E. (2015) Mutu Pelayanan Kesehatan dan Kebidanan. Yogyakarta: PT Pustaka Baru. 